\title{
Potencialidades y limitaciones en la construcción de una política soberana de cooperación internacional en Ecuador (2007-2013)
}

\author{
Editado por/Edited by: Johanna Andrango \\ Recibido/Received: 26/01/2014. Aceptado/Accepted: 15/05/2014 \\ Publicado en línea/Published on Web: 10/09/2014
}

\author{
Bruno Ayllón \\ Docente e investigador PROMETEO en la Escuela de Relaciones Internacionales "José Peralta", Instituto \\ de Altos Estudios Nacionales (IAEN). \\ Correo electrónico: bruno.ayllon@iaen.edu.ec
}

\section{Resumen}

La llegada al poder de Rafael Correa en 2007 inauguró un nuevo periodo en la realidad política y económica ecuatoriana: la Revolución Ciudadana. A las transformaciones del ordenamiento jurídico deben añadirse cambios en los procesos de planificación, la recuperación de la capacidad reguladora del Estado y la elaboración de Planes Nacionales del Buen Vivir (PNBV). Al mismo tiempo se emprendió un giro a la política exterior. Se revisó la cooperación recibida y se inició el proceso de construcción de una política pública que impulsara la Cooperación Sur - Sur (CSS).

Palabras clave: Buen Vivir, Revolución Ciudadana, Cooperación Sur - Sur, Cooperación Internacional.

\section{Abstract}

The rise to power of Rafael Correa in 2007 started a new period in the political and economic reality of Ecuador: the Citizen Revolution. Changes in the planning process - its main focus being the recovery of the State's regulatory capacity as well as the development of Nationals Plans for Good Living (PNBV) - must be added to the transformations of the legal system. Besides, a turn in the foreign policy was implemented. Foreign cooperation was reviewed and a process of building up a public policy was initiated to drive South - South Cooperation.

Palabras clave: Good Living, Citizen Revolution, South - South Cooperation, International Cooperation.

La llegada al poder, el 15 de enero de 2007, de Rafael Correa Delgado y del Movimiento Alianza País (Patria Altiva y Soberana) inauguró -más allá de las evaluaciones que se realicen- un nuevo periodo en las dinámicas políticas, económicas y sociales del Ecuador. A las transformaciones experimentadas en el ordenamiento jurídico, cuya máxima expresión fue la aprobación en referéndum de la Constitución de Montecristi, debe añadirse la reestructuración del Estado y la recuperación de sus capacidades rectoras, planificadoras, coordinadoras y reguladoras de las políticas públicas, después de un largo periodo de debilitamiento en la "larga noche neoliberal", como reitera el Presidente de la República.

La formulación y puesta en marcha del Plan Nacional de Desarrollo (2007-2010) y de los sucesivos Planes Nacionales del Buen Vivir (PNBV) puede considerarse la plasmación concreta del proceso descrito anteriormente. De esta forma, el gobierno de la "Revolución Ciudadana" reasumía la dirección política del proceso de desarrollo nacional y de su inserción interna- cional con una propuesta, ya experimentada por otros países latinoamericanos y por algunas potencias emergentes, que perseguía "crear un amplio conjunto de instituciones formales para gobernar los mercados" (Rodrik, 2011).

Así lo establece claramente el PNBV 2013-2017 al considerar que "la cooperación internacional es un instrumento de política exterior de los Estados" que debe coincidir con las necesidades de "la sociedad ecuatoriana detectadas por su gobierno". Puesto que la transformación de la matriz productiva es "imprescindible” según el PNBV, "el Estado tiene la obligación de conducir los eventuales recursos de la cooperación" al cumplimiento de esos objetivos y metas" (SENPLADES, 2013).

Al mismo tiempo se imprimió un giro a la política exterior con decisiones de gran simbolismo, como la no renovación del convenio de instalación y funcionamiento de la base militar estadounidense en Manta, el rechazo a las iniciativas de libre comercio impulsadas por Washington, y el consecuente ingreso en la Alianza Bolivariana para los Pueblos de Nuestra América 
(ALBA), o la participación activa en el proceso de configuración institucional de Unión de Naciones Suramericanas (UNASUR), cuya Secretaría General se ubicó en Quito. Todas estas medidas pueden interpretarse como una decidida apuesta por el fortalecimiento del eje Sur - Sur en las relaciones internacionales del país. Vale recalcar que en este artículo se hará referencia sólo a la Cooperación Internacional No Reembolsable (CINR), es decir, aquella cuya coordinación y gestión corresponde a la Secretaría Técnica de Cooperación Internacional (SETECI).

\section{La gestión soberana de la Cooperación}

Es en este marco en el que se inscribe la revisión de la cooperación internacional recibida y el inicio de la construcción de una política pública para impulsar la cooperación ofrecida por Ecuador, considerada como "una oportunidad para multiplicar los nexos Sur - Sur y cimentar la diversificación de sus relaciones exteriores" (SENPLADES, 2013).

En la primera dimensión, la prioridad fue garantizar el alineamiento de la cooperación internacional a las nuevas orientaciones gubernamentales del desarrollo nacional a través de un proceso de racionalización administrativa y gerencial regido por el objetivo de alcanzar una "gestión soberana" de los recursos recibidos en la CINR. Cuatro ejes fundamentales articularon estos esfuerzos. En primer lugar, asegurar que los principios rectores de las relaciones internacionales, según los preceptos constitucionales, fuesen la brújula de la cooperación en Ecuador, es decir, lograr su compatibilidad con "la independencia e igualdad jurídica de los Estados, la convivencia pacífica y la autodeterminación de los pueblos, así como la cooperación, la integración y la solidaridad" (Artículo 416).

En segundo lugar crear un sistema de monitoreo, control y registro de la información sobre la cooperación presente en Ecuador. Era necesario revertir la tendencia de los cooperantes a operar "puenteando" a las instituciones públicas, con los consecuentes impactos negativos en lo referente a la dispersión, fragmentación y falta de alineamiento de los proyectos e iniciativas de las agencias públicas y privadas de cooperación de los países donantes. Sólo de esta manera la cooperación internacional podría complementar los esfuerzos nacionales y articularse con las estrategias de desarrollo reflejadas en los PNBV.

Algunas medidas adoptadas fueron la utilización del sistema nacional de planificación, de finanzas y de contratación públicas para seleccionar los proyectos, para centralizar los recursos financieros de los donantes en una cuenta única del Banco Central y para transparentar y reducir los costes en la ejecución de la cooperación (Rosero, 2012a). También se inscribe en esta lógica la regularización de las actividades de las ONG internacionales en Ecuador.

En tercer lugar, dar cumplimiento a las disposiciones constitucionales que confieren a los Gobiernos Autónomos Descentralizados (GAD) la capacidad de "gestionar la cooperación internacional para el cumplimiento de sus competencias". Posteriormente, el Código Orgánico de Organización Territorial Autonomía y Descentralización (COOTAD) y el Código Orgánico de Planificación y Finanzas Públicas establecieron que "los GAD podrán gestionar la obtención de recursos de la cooperación internacional y asistencia técnica para el cumplimiento de sus competencias propias en el marco de los objetivos nacionales, de sus planes de desarrollo y de los principios de equidad, solidaridad, subsidiariedad, interculturalidad, oportunidad y pertinencia" (art. 131 / art.68).

Este proceso de descentralización de la gestión cooperación internacional -no exento de tensiones entre SETECI y los GAD y entre las propias asociaciones y consorcios que nuclean a los GAD-, fue impulsado por el Consejo Nacional de Competencias que resolvió "transferir e implementar la competencia de la gestión de la cooperación internacional para la obtención de recursos no reembolsables y asistencia técnica para el cumplimiento de sus competencias a los GAD" (Resolución n ${ }^{\circ}$ 0001CNC-2011).

En cuarto lugar, adoptar los acuerdos internacionales sobre eficacia y calidad de la cooperación, en especial la Declaración de París que fue suscrita por Ecuador en 2009. De esta manera, la cooperación internacional estaría obligada a seguir los principios de alineación, apropiación, armonización, gestión basada en resultados y mutua responsabilidad. Estas disposiciones son la clave para interpretar la no renovación del programa de cooperación con la Agencia Estadounidense de Ayuda Internacional (USAID), decisión conocida a finales de 2013, como consecuencia de las resistencias de Washington a cumplir con los mismos principios en Ecuador que su gobierno había rubricado en 2005.

\section{La Cooperación Sur - Sur de Ecuador}

En la segunda dimensión, el vigor y la pujanza de la Cooperación Sur - Sur (CSS) en Latinoamérica y en Ecuador se relacionan con las transformaciones políticas, sociales, económicas y culturales de hondo calado en la región y en el país andino en este siglo XXI. Por otra parte, y como elemento destacado, el regionalismo posliberal se ha convertido en un factor de impulso de la CSS y los procesos de integración, concertación y cooperación que proliferan (UNASUR, CELAC, ALBA) se han brindado como plataformas de proyección y diseminación de la misma.

En estos campos la experiencia de Ecuador es muy representativa de la construcción de un modelo propio de cooperación. Aunque los recursos del país sean modestos y sus capacidades todavía presenten limitaciones en proceso de superación, existe una firme voluntad política de compartir las experiencias y conocimientos ecuatorianos con otros países latinoamericanos a través de la CSS. El propio canciller Ricardo Patiño manifestó que el fundamento de la CSS consistía en "poner las fortalezas de cada uno de nuestros países en políticas sociales al servicio de otros asegurando que la población pueda disfrutar de mejores condiciones de vida".

Para ello, según la visión oficial, se está impulsando una política pública de cooperación basada en el intercambio ético y en los éxitos de la Revolución Ciudadana en modificar las condiciones que aseguren "la construcción de relaciones simétricas entre iguales que faciliten la economía endógena para el buen vivir y la generación de pensamiento propio" (SENPLADES, 2013).

La visión política de medio plazo sobre la CSS del Ecuador y sus contribuciones al desarrollo nacional se encuentran formuladas en el PNBV 2013-2017. El objetivo número 12 titulado "Garantizar la soberanía y la paz, profundizar la inserción estratégica en el mundo y la integración latinoamericana" dedica 
una especial atención a la importancia que ha cobrado la CSS en un contexto de acelerada globalización, de desplazamiento de la ayuda tradicional hacia otras regiones del mundo y de creciente disposición de muchos países en desarrollo para asumir un rol destacado como actores en la cooperación internacional.

Con estos antecedentes se afirma que "la Cooperación Sur - Sur va más allá de encontrar nuevos actores en el envío de recursos para el desarrollo e involucra una nueva forma de pensar la cooperación, entre pares y en realidades concretas (...) La Cooperación Sur - Sur muestra que estas acciones han logrado posicionarse de manera importante en la cooperación internacional, estableciendo una fuente de desarrollo en la región y una diversidad de acciones destinadas a incidir en los ámbitos internos sociales, económicos, culturales, de medio ambiente e institucionales de cada país" (SENPLADES, 2013).

Es en un nivel inferior, en las políticas y lineamientos estratégicos, numeral 12.7, donde se establece la consolidación de una "gestión soberana de la cooperación internacional, en consonancia con la transformación de la matriz productiva y el fortalecimiento de la CSS". En efecto, se señalan como prioridades el fortalecimiento de la CSS como instrumento de integración regional y binacional; la potenciación de la oferta de cooperación técnica ecuatoriana hacia otros países, con énfasis en la región latinoamericana; la promoción de una gestión articulada y coordinada de la cooperación internacional y el fomento de acuerdos bilaterales de cooperación económica, técnica y productiva con las nuevas economías emergentes.

En lo concreto, Ecuador contempla en la cooperación un instrumento de fortalecimiento y diversificación de sus relaciones exteriores y de multiplicación de sus relaciones Sur Sur. Pero lo hace con una concepción rupturista que aboga por "construir lazos que transmitan hacia otras sociedades recursos, conocimientos y experiencias que permitan a poblaciones de otras partes del mundo beneficiarse de lo que se crea en el país" (SENPLADES, 2013).

Más allá del discurso, se registran cambios organizativos relevantes. Desde la disolución del Instituto Nacional Ecuatoriano de Cooperación Internacional (INECI) vinculado a SENPLADES, en 2007, y desde la transformación de la Agencia Ecuatoriana de Cooperación Internacional (AGECI) en Secretaría Técnica de Cooperación Internacional (SETECI) adscrita a Cancillería, se han fortalecido las capacidades humanas e institucionales del denominado Sistema Ecuatoriano de Cooperación Internacional. También se ha enfatizado el potencial de la cooperación como "herramienta de política exterior clave en el fortalecimiento de los procesos de integración regional" y en la articulación de "una voz del Sur y para el Sur" (Rosero, 2012b).

Además, se constata un giro reciente, a partir de la renovación del mandato presidencial, en 2013, por el cual se quiere imprimir a la cooperación internacional, tanto a la recibida como a la que se ofrece, un papel de instrumento catalizador al servicio de la generación de "talento humano y del cambio de la matriz productiva". La reciente publicación, en 2013, de una nueva edición actualizada del Catálogo de Asistencia Técnica Ecuatoriana, permitirá incrementar la oferta de cooperación nacional siempre y cuando vaya acompañada de recursos financieros y personal directivo y técnico para que las instituciones públicas tengan capacidad de compartir sus experiencias. Igualmente, se afirma en los discursos de las autoridades de SETECI la idea de "cooperación como forma de vida". Esta visión valoriza la idiosincrasia del saber ecuatoriano y recupera prácticas e instituciones sociales ancestrales basadas en la reciprocidad, la solidaridad y la redistribución en el mundo andino, como la minga, la maquimañachina o la maquipurarina (De la Torre, 2004).

Este viraje se relaciona con la transición de receptor de recursos de Ayuda Oficial al Desarrollo (AOD) a oferente de acciones y proyectos bajo la modalidad de CSS que Ecuador inicia a partir de 2008 y con la caída de flujos de AOD que el país recibía. Según datos de la OCDE (2012), Ecuador es un país escasamente dependiente de la ayuda internacional.

Los recursos anuales de AOD de los donantes de la OCDE representan apenas el 0,3\% del PIB nacional, es decir, unos US\$ 171 millones en 2011. Según la SETECI (2013), en el año 2012, el principal cooperante en el Ecuador fue España con una asignación de recursos del 18\% del total, seguida de la Unión Europea $(17,2 \%)$ y Estados Unidos (13,6 \%). Siguen a estos tres donantes Corea del Sur (8,4 \%), Naciones Unidas (7, $8 \%$ ) y Alemania (6,5\%). Esos seis cooperantes concentran el 71,5 $\%$ del total de la CINR en el país (SETECI, 2013).

Pero la cooperación de Ecuador no se reduce apenas a las declaraciones de intenciones o a las formulaciones retóricas. El país viene incrementando el número de proyectos de CSS en los que participa, sea en calidad de receptor o de oferente. En cuanto a la primera categoría, los datos de los Informes de la Secretaría General Iberoamericana (SEGIB) nos muestran que, en el año 2011, las instituciones y administraciones públicas ecuatorianas participaron como receptoras en 37 proyectos y 12 de acciones de menor escala de países latinoamericanos, siendo Brasil, Argentina y México los principales oferentes.

Algunos ejemplos de estos proyectos fueron el apoyo a la creación de un sistema de información nacional de recursos hídricos forestales (con Brasil); proyectos de asistencia técnica, capacitación y gestión hidro-informática en sistemas integrados de gestión en empresas de agua potable y saneamiento (con México); o la cooperación minera y metalúrgica y el fortalecimiento del sistema ecuatoriano de trasplantes (con Argentina). En el conjunto iberoamericano, Ecuador fue responsable en calidad de receptor, del $6,3 \%$ del total de los proyectos realizados en el año 2011 (Xalma, 2013). Ver Tabla 1.

En la segunda categoría, la de oferente de cooperación, el número de proyectos $\mathrm{y}$ acciones registrados son menores que en la categoría de receptor, pero con una marcada tendencia incremental. Sin embargo, en el conjunto de la CSS iberoamericana, los proyectos ecuatorianos representan apenas el 1,7\% del total. En 2011, Ecuador realizó 10 proyectos y otras 10 acciones en Latinoamérica siendo Paraguay, Venezuela, El Salvador, Perú y República Dominicana los países de destino de esas iniciativas. Por sectores, la cooperación ecuatoriana se centró en el sector económico ( $50 \%$ de los proyectos con $80 \%$ de los mismos en infraestructura y servicios y $20 \%$ en el sector social; y $30 \%$ en otros sectores). Ver Tabla 2.

Ejemplos de estas iniciativas fueron el proyecto con Paraguay para el aprovechamiento turístico de áreas protegidas a partir de la experiencia de las Islas Galápagos y cooperación 
en materia de planificación; con Perú, el programa de conservación de bosques nativos (Socio-bosque) ejecutado por el ministerio del medio ambiente; con El Salvador, en el intercambio de experiencias entre economías dolarizadas, con asistencias técnicas para el diseño, constitución y funcionamiento de un Fondo de Liquidez para el sistema financiero que permita mayor capacidad de respuesta ante choques externos; con varios países el intercambio de experiencias en materia de discapacidad a través de la misión Manuela Espejo.

Aún debe registrarse el ofrecimiento de ayuda humanitaria por parte de Ecuador en situaciones de desastres naturales a Chile, Haití y Colombia (2010), El Salvador (2010 y 2011), Nicaragua (2011) o Panamá y Venezuela (2010). Cabe señalar que esta orientación geográfica y temática viene en buena parte determinada por las disposiciones del PNBV 2013 - 2017 donde se establece que "el entorno latinoamericano inmediato es el objeto de la cooperación ecuatoriana que se materializa en la recepción de estudiantes y profesores de fuera, en la transmisión de conocimientos, en la colaboración para misiones de mantenimiento de la paz y en la socialización de experiencias de gestión pública" (SENPLADES, 2013).

\section{Los desafíos del presente y del futuro}

El caso ecuatoriano ilustra las potencialidades de la Cooperación Sur - Sur de aquellos países latinoamericanos que, aun siendo pequeños, pueden contribuir con su filosofía y sus prácticas a diversificar y enriquecer el panorama de la cooperación internacional. No obstante, es necesario identificar los obstáculos presentes en este proceso, relacionados con factores que dificultan el crecimiento y consolidación de la cooperación ecuatoriana.

El primero de ellos es el desafío político. En efecto, la gestión de la cooperación internacional en Ecuador ha sufrido los embates de las diferentes perspectivas políticas, según los modelos de desarrollo imperantes en cada fase, y de las disputas inter-burocráticas propias de aquellos sectores de la administración pública que movilizaban recursos externos de los donantes y favorecían el fondeo o "caja chica" de ciertas instituciones nacionales y locales. A finales de los años 90, la cooperación internacional se gestionaba desde el Ministerio de Economía y Finanzas, en concreto desde la Agencia Ecuatoriana de Cooperación Externa (AGECE).

A inicios del siglo XXI, esta agencia fue sustituida por el Instituto Ecuatoriano de Cooperación Internacional (INECI) vinculado al Ministerio de Relaciones Exteriores y que dio paso, en 2007, a la Agencia Ecuatoriana de Cooperación Internacional (AGECI), adscrita a la SENPLADES. Sin embargo, en un nuevo cambio demostrativo de la inestabilidad de la institucionalidad de la cooperación, en el año 2010, se produjo la extinción de AGECI y su sustitución por la Secretaría Técnica de Cooperación Internacional (SETECI), dependiente del entonces Ministerio de Relaciones Exteriores, Comercio e Integración, hoy denominado Ministerio de Relaciones Exteriores y Movilidad Humana (MREMH).

Frente a este "baile de sillas" cabría la posibilidad de considerar la futura adscripción de SETECI, o de órgano equivalente, directamente a la Presidencia de la República, aunque manteniendo algún tipo de vinculación al MREMH. Esta ha sido la fórmula exitosa seguida, por ejemplo, en Uruguay, donde bajo el gobierno de José Mujica fue creada la Agencia Uruguaya de Cooperación Internacional que gracias a la estabilidad otorgada por su decreto constitutivo es considerada hoy en día un ejemplo para la gestión de la cooperación en Latinoamérica. Mientras tanto, sería deseable una mayor vinculación real entre SETECI y el MREMH para, en primer lugar, potenciar y hacer coherentes los discursos y las prácticas de las dos instituciones $\mathrm{y}$, en segundo lugar, para unificar criterios sobre el papel de la cooperación como instrumento de la política exterior, permitiendo así una mayor proyección de las políticas y experiencias ecuatorianas de desarrollo.

El segundo desafío es el jurídico- institucional. En efecto, algunos países latinoamericanos, como México, han elevado al máximo rango legal todos los aspectos referentes a la cooperación internacional, tanto a la Norte - Sur, a la multilateral como a la Sur - Sur. La elaboración de un proyecto de ley de cooperación internacional en Ecuador se presenta hoy como una necesidad urgente. Es necesario recoger en una única norma el disperso corpus legal y administrativo que regula la cooperación "en" y "de" Ecuador. También apremia adaptar a las nuevas realidades de la cooperación internacional y al diferente perfil de Ecuador - como país en desarrollo con capacidad de brindar sus conocimientos y experiencias - las estructuras políticas, de planificación, gestión y financiación tanto de la cooperación recibida como de la ofrecida.

El tercero de los desafíos a enfrentar es el del desarrollo de capacidades técnicas, financieras y humanas en los agentes de la cooperación ecuatoriana. Es necesario fortalecer las capacidades rectoras, planificadoras y ejecutoras de SETECI con el objetivo de incrementar y acelerar la coordinación con los demás agentes del Sistema Ecuatoriano de Cooperación Internacional (SECI), especialmente con los GAD. Por otra parte, la profesionalización de la gestión de la cooperación es una tarea deseable. Son necesarias mayores dotaciones presupuestarias y sistemas de incentivos para la estabilidad laboral de técnicos y directivos, especialmente en SETECI, evitando así el excesivo carácter rotativo que se observa en su personal. Por supuesto, también en las instituciones ejecutoras de la cooperación ofrecida (Ministerios y Secretarias) y sobre todo de la Cancillería.

Incrementar la formación de los puntos focales de la cooperación en esas instituciones y capacitar a los diplomáticos ecuatorianos son labores fundamentales para hacer de las representaciones en el exterior antenas de emisión de las experiencias nacionales de desarrollo y de recepción de las demandas de los países socios. Por cierto, la diversificación de las fuentes y sectores tradicionales de la cooperación recibida por el país, especialmente entre los países emergentes por sus potenciales aportaciones al proceso de cambio de la matriz productiva y generación de talento humano, se beneficiaría de la mejora de las capacidades de los funcionarios públicos.

Desde luego, ninguno de los desafíos enumerados y descritos será posible sin la creación de instrumentos financieros que garanticen el fondeo de esas iniciativas de cooperación. La constitución de un fondo para la Cooperación Sur - Sur de Ecuador, aunque pueda tener inicialmente un carácter modesto, emitiría una señal positiva del compromiso del gobierno con la cooperación.

\section{Referencias}

De la Torre, L. M. (2004). La reciprocidad en el mundo andino. El caso del pueblo de Otavalo. Quito: Abya-Yala/ILDIS-FES. 
Rodrik, D. (2011). La paradoja de la globalización. Barcelona.

Rosero, G. (2012a). La Cooperación Internacional en tiempos de Revolución Ciudadana. Línea Sur, 104-116.

Rosero, G. (2012b). Una plataforma de discusión política para la cooperación en América Latina. Cooperamos.

SENPLADES. (2013). Plan Nacional del Buen Vivir 20132017. Quito.

SETECI. (2013). Por una cooperación internacional que impulse el desarrollo. Diplomacia Ciudadana.

Xalma, C. (2013). El renovado auge de la Cooperación Sur - Sur: la experiencia iberoamericana. (BID-INTAL, Ed.) Integración y Comercio(36), 29-42.

\section{Anexos}

Tabla 1: Ecuador como receptor de la CSS en el año 2011

\begin{tabular}{|l|c|c|}
\hline País oferente & $\begin{array}{c}\text { Número de } \\
\text { proyectos }\end{array}$ & $\begin{array}{c}\text { Número de } \\
\text { acciones }\end{array}$ \\
\hline Argentina & 9 & 3 \\
\hline Brazil & 10 & 1 \\
\hline Chile & 4 & - \\
\hline Colombia & - & 1 \\
\hline Cuba & 2 & 1 \\
\hline El Salvador & 1 & - \\
\hline México & 9 & 1 \\
\hline Perú & 1 & 4 \\
\hline Paraguay & 1 & 1 \\
\hline TOTAL & $\mathbf{3 7}$ & $\mathbf{1 2}$ \\
\hline
\end{tabular}

Fuente: Informe de la Cooperación Sur - Sur en Iberoamérica 2012, estudios $S E G I B n^{\circ} 7$.

Tabla 2: Ecuador como oferente de la CSS en el año 2011

\begin{tabular}{|l|c|c|}
\hline \multicolumn{1}{|c|}{ País oferente } & $\begin{array}{c}\text { Número de } \\
\text { proyectos }\end{array}$ & $\begin{array}{c}\text { Número de } \\
\text { acciones }\end{array}$ \\
\hline El Salvador & 2 & 1 \\
\hline Paraguay & 3 & 7 \\
\hline Perú & 1 & 2 \\
\hline Rep. Dominicana & 1 & - \\
\hline Venezuela & 3 & - \\
\hline TOTAL & $\mathbf{1 0}$ & $\mathbf{1 0}$ \\
\hline
\end{tabular}

Fuente: Informe de la Cooperación Sur - Sur en Iberoamérica 2012, estudios SEGIB $n^{\circ} 7$. 